ROSA, P. A. L.; ALVES, M. C.; VIDEIRA, L. M. L.; BONINI, C. B. S. Recuperação de um solo de cerrado após 19 anos: ocorrência espontânea de espécies arbóreas. Revista de Agricultura Neotropical, Cassilândia-MS, v. 1, n. 1, p. 44-57, jul./set. 2014.

\title{
RECUPERAÇÃO DE UM SOLO DE CERRADO APÓS 19 ANOS: OCORRÊNCIA ESPONTÂNEA DE ESPÉCIES ARBÓREAS
}

\section{POLIANA APARECIDA LEONEL ROSA ${ }^{1}$, MARLENE CRISTINA ALVES ${ }^{2}$, LIGIA MARIA LUCAS VIDEIRA ${ }^{1}$, CAROLINA BATISTA DOS SANTOS BONINI ${ }^{1}$}

\footnotetext{
${ }^{1}$ UNESP/Ilha Solteira-SP. polirosa1@hotmail.com, ligiavideira@hotmail.com, carolsbatistabonini@hotmail.com ${ }^{2}$ Docentes/UNESP/Ilha Solteira-SP. mcalves.agr.feis.unesp.br
}

RESUMO: A intervenção humana com a retirada das camadas superficiais do solo para obras civis, tem resultado em extensas áreas degradadas. Através deste trabalho objetivou-se avaliar o grau de recuperação de um solo, após 19 anos, sob diferentes intervenções para sua recuperação e a ocorrência espontânea de espécies arbóreas. Os tratamentos foram instalados em 1992. Utilizou-se o delineamento experimental em blocos casualizados com sete tratamentos e quatro repetições, sendo os tratamentos compostos por diferentes métodos de regeneração. Em 1999 realizou-se semeadura de Urochloa decumbens Stapf em toda a área experimental. Foram avaliados o desenvolvimento das espécies arbóreas, que se regeneraram naturalmente na área, e a massa seca da parte aérea da $U$. decumbens. Os tratamentos de recuperação do solo estão sendo promissores e a ocorrência de espécies arbóreas de Cerrado e os seus desenvolvimentos têm sido bons indicadores de recuperação do mesmo. Das sete espécies de plantas que se regeneraram naturalmente dentro da área experimental, a espécie que mais se adaptou foi o Jacarandá-do-campo (Machaerium acutifolium Vogel). O tratamento feijão-de-porco após o guandú, com aplicação de calcário no solo, foi mais eficiente quando comparado ao tratamento solo mobilizado com vegetação espontânea.

PALAVRAS-CHAVE: Área degradada, adubos verdes, calcário, gesso, Urochloa decumbens.

\section{RECOVERY OF A SOIL AFTER 19 YEARS OF SAVANNAH: SPONTANEOUS OCCURRENCE OF TREE SPECIES}

\begin{abstract}
Human intervention with removal of topsoil for civil works has resulted in extensive degraded areas. Through this work aimed to evaluate the degree of recovery of a soil after 19 years under different interventions for their recovery and spontaneous occurrence of tree species. The treatments were installed in 1992 the experimental design was randomized complete block with seven treatments and four replications, with treatments consisting of different regeneration methods. In 1999 was held sowing Urochloa decumbens throughout the experimental area. Development of tree species that naturally regenerated in the area and dry mass of shoots of $U$. decumbens were evaluated. The treatments of soil recovery are promising and the occurrence of tree species from Cerrado and its developments have been good indicators of recovery of the same. Of the seven plant species that regenerated naturally within the experimental area, the species most adapted was the Rosewood-of-field (Machaerium acutifolium Vogel). Treatment beans pig-after pigeonpea, with application of lime in the soil, was more efficient when compared to treatment with Solo mobilized spontaneous vegetation.
\end{abstract}

KEY WORDS: Degraded area, green manures, limestone, gypsum, Urochloa decumbens. 


\section{INTRODUÇÃO}

Durante a década de 1960, com a necessidade do aumento na disponibilidade energética do Brasil, deu-se início à construção de um conjunto de hidrelétricas para o suprimento desta demanda. Porém, como não havia tantos conhecimentos em relação ao meio ambiente restaram como cicatrizes dessas construções as chamadas áreas de empréstimos, que são as áreas de onde foi retirado o solo necessário para a construção da barragem de uma hidroelétrica. Após sua retirada, restou uma área com aspecto lunático e com subsolo exposto altamente compactado, com suas capacidades físicas e químicas totalmente comprometidas (BONINI; ALVES, 2012).

Para a construção da barragem de Ilha Solteira, foram necessários grandes volumes de solo, restando áreas com solo exposto nas regiões próximas a esta hidrelétrica desde 1969. No intuito de restabelecer um solo com características físico-químicas mais próximas ao natural, em 1992 iniciaram diferentes intervenções em uma área experimental situada nestas áreas de solo exposto, mas para isto, conhecimentos básicos associados à correção das restrições do solo ao crescimento das plantas se fizeram necessários na definição de metodologias para recuperação de áreas degradadas.

Segundo Martins et al. (2004), nas últimas três décadas, registrou-se na região CentroOeste grandes mudanças no uso da terra. Extensas áreas com vegetação nativa foram substituídas por outras formas de usos deixando vastas áreas com solos expostos e degradados. Dentro destes problemas pode-se citar a remoção de espessas camadas do solo original, que estão provocando a compactação do substrato e de horizontes mais profundos. Além destes problemas na estrutura, a atividade biológica do solo e disponibilidade de água também é influenciada, pois o suprimento de nutrientes essenciais como fósforo, enxofre e principalmente nitrogênio às plantas é prejudicado.

Assim de acordo com Meloet al. (2007), a vegetação que se instala nesses solos é usualmente empobrecida e de desenvolvimento lento, associada à baixa capacidade de retenção de água e íons, constituindo importante limitação à capacidade produtiva dos solos.

Avaliar a revegetação e o grau de cobertura do solo não é tão simples quanto aparenta ser. É necessário observar uma série de fatores biológicos que interferem no surgimento, adaptação e o desenvolvimento das espécies vegetativas na área em estudo. Dentre esses fatores pode-se citar: banco de sementes de plantas no local, fauna eutrófica presente, fatores climáticos (vento, precipitação e fotoperíodo), tipo de solo (incluindo seus fatores físicos e químicos), animais que circundam a área e promovem disseminação dos frutos e sementes, relevo e topografia da região, e tudo isso dará condições adequadas ou não para que ocorra germinação. Por outro lado tem que se levar em conta que o solo em estudo foi decapitado devido à terraplanagem realizada, fazendo com que do mesmo fosse eliminado além da vegetação presente, o seu banco de plântulas, de sementes e de rebrota, que eram seus meios de regeneração bióticos.

Os principais problemas edáficos encontrados em áreas remanescentes de construção civil são: a compactação do material exposto, as baixas taxas de infiltração e capacidade de armazenamento de água, a deficiência de oxigênio, a alta resistência à penetração das raízes, o aumento da densidade do solo e a falta de matéria orgânica no mesmo; prejudicando também sua aeração (CORRÊA et al., 1998). A recuperação de tais áreas degradadas está sendo feita por meio de tratamentos físico-mecânicos do solo, calagem, gessagem, introdução de plantas de cobertura e adubos verdes para recuperar o mesmo pela produção e incorporação de matéria orgânica, regeneração e sucessão ecológica, e sistemas agroflorestais. 
É necessária a interferência humana para favorecer a aceleração do processo de recuperação natural nas áreas degradadas (SILVA; CORRÊA, 2008). Uma maneira de intervenção comumente utilizada é a realização do preparo do solo, visando melhorar sua qualidade.

É importante corrigir a acidez do solo, pois ela afeta o rendimento das plantas, pela influência que exerce sobre a fertilidade do mesmo, afetando no rendimento, disponibilidade e assimilação dos nutrientes pelas plantas e eficiência da adubação (VIEIRA et al., 2007). Ela pode ser corrigida por meio da aplicação de corretivos que neutralizam a acidez dos solos e ainda podem carrear nutrientes vegetais ao mesmo, principalmente cálcio e magnésio (RAMOS et al., 2006).

$\mathrm{O}$ uso de culturas destinadas à cobertura do solo também é uma estratégia para que haja melhorias na qualidade ambiental, pois protege o solo dos agentes climáticos, mantém ou até aumenta o teor de matéria orgânica no solo, mobilizando e reciclando nutrientes, beneficiando também a atividade biológica do solo (ARGENTON et al., 2005). Essas culturas são responsáveis pela estruturação do solo por meio do sistema radicular, pois além de outros fatores, é possível citar que, quanto mais penetrado no solo o sistema radicular estiver, maior será a produção de biomassa, e mais descompactado o solo ficará.

Para fazer emprego de algumas plantas como cobertura vegetal do solo, seja como adubo verde ou como cobertura morta, um dos pontos mais importantes é a necessidade de selecionar espécies que se desenvolvam bem em solos de baixa a média fertilidade, adaptemse bem a valores baixos de $\mathrm{pH}$ do solo (PEREIRA, 2008) e tenham um bom crescimento vegetativo para poder produzir grande quantidade de massa vegetal.

A utilização de princípios ecológicos de sucessão vegetal, em ecossistemas degradados, constitui um importante fator para sua reabilitação, pois se está utilizando os próprios mecanismos da natureza local, induzindo o surgimento de novos estágios sucessionais (VALCARCEL; SILVA, 2000). É necessário enfatizar, que para se realizar a regeneração de uma vegetação, primeiramente criam-se condições que estimulam os caminhos da sucessão (ANAND; DESROCHERS, 2004), então se faz a estabilização da paisagem e a implantação de cobertura vegetal no local, para que se possa contribuir acelerando o processo de recuperação da área degradada.

Neste sentido, objetivou-se a avaliação do grau de recuperação de um solo degradado, após 19 anos de diferentes intervenções para sua recuperação, por meio da avaliação da sucessão ecológica das espécies arbóreas.

\section{MATERIAL E MÉTODOS}

O trabalho foi conduzido na Fazenda de Ensino, Pesquisa e Extensão da Faculdade de Engenharia - UNESP, Campus de Ilha Solteira, no município de Selvíria, MS. A área está situada entre as coordenadas geográficas de $51^{\circ} 24^{\prime}$ de longitude oeste de Greenwich e $20^{\circ}$ 22' de latitude sul, com altitude de 339 metros (Figura 1).

O tipo climático da região é classificado como Aw de acordo com Köppen, com precipitação média anual de $1370 \mathrm{~mm}$, temperatura média anual de $23,5^{\circ} \mathrm{C}$ e umidade relativa do ar entre 70-80 \% (média anual). O solo foi classificado de acordo com recomendações de Demattê (1980), como Latossolo Vermelho-Escuro distrófico, textura franco argilo-arenosa (302, 172 e $526 \mathrm{~g} \mathrm{~kg}^{-1}$ de argila, silte e areia, respectivamente), muito profundo, rico em sesquióxidos. Pela nomenclatura atual do Sistema Brasileiro de Classificação do solo é um Latossolo Vermelho distrófico (SANTOS et al., 2013).

O experimento teve início no ano de 1992, em um subsolo exposto desde 1969 (Figura 
2) pela remoção de uma camada de solo de $8,6 \mathrm{~m}$ de espessura para a terraplanagem e fundação da Usina Hidrelétrica de Ilha Solteira, SP (ALVES; SOUZA, 2008). Utilizou-se o delineamento experimental em blocos casualizados, com sete tratamentos e quatro blocos. Cada parcela teve área de $100 \mathrm{~m}^{2}(10 \times 10 \mathrm{~m})$, e cada bloco com espaçamento de $2 \mathrm{~m}$ entre si. Foram utilizados os seguintes tratamentos:

1) SM/U - Solo mobilizado (vegetação espontânea);

2) MP/U - Semeadura de mucuna-preta - (Stizolobium aterrium Piper e Tracy);

3) G/FP/U - Semeadura de feijão-guandu (Cajanus cajan (L.) Millsp) até 1994, após substituído por feijão-de-porco (Canavalia ensiformis (L.) DC);

4) $\mathrm{C}+\mathrm{MP} / \mathrm{U}$ - Aplicação de calcário + semeadura de mucuna-preta;

5) $\mathrm{C}+\mathrm{G} / \mathrm{FP} / \mathrm{U}$ - Aplicação de calcário + semeadura de feijão-guandu até 1994, após substituído por feijão-de-porco;

6) $\mathrm{C}+\mathrm{Ge}+\mathrm{MP} / \mathrm{U}$ - Aplicação de calcário + gesso + semeadura de mucuna-preta;

7) $\mathrm{C}+\mathrm{Ge}+\mathrm{G} / \mathrm{FP} / \mathrm{U}$ - Aplicação de calcário + gesso + semeadura de feijão guandu até 1994, após substituído por semeadura de feijão-de-porco.

Ainda foram utilizadas duas testemunhas nas avaliações, estas localizadas fora da área experimental:

- SE (Solo exposto sem técnica de recuperação) e

- MA (Mata nativa de Cerrado).

Em 1999, foi realizada a semeadura de Urochloa decumbens Stapf. (U) em toda a área experimental, com o objetivo de proteger e acumular matéria orgânica ao solo (Figura 3).

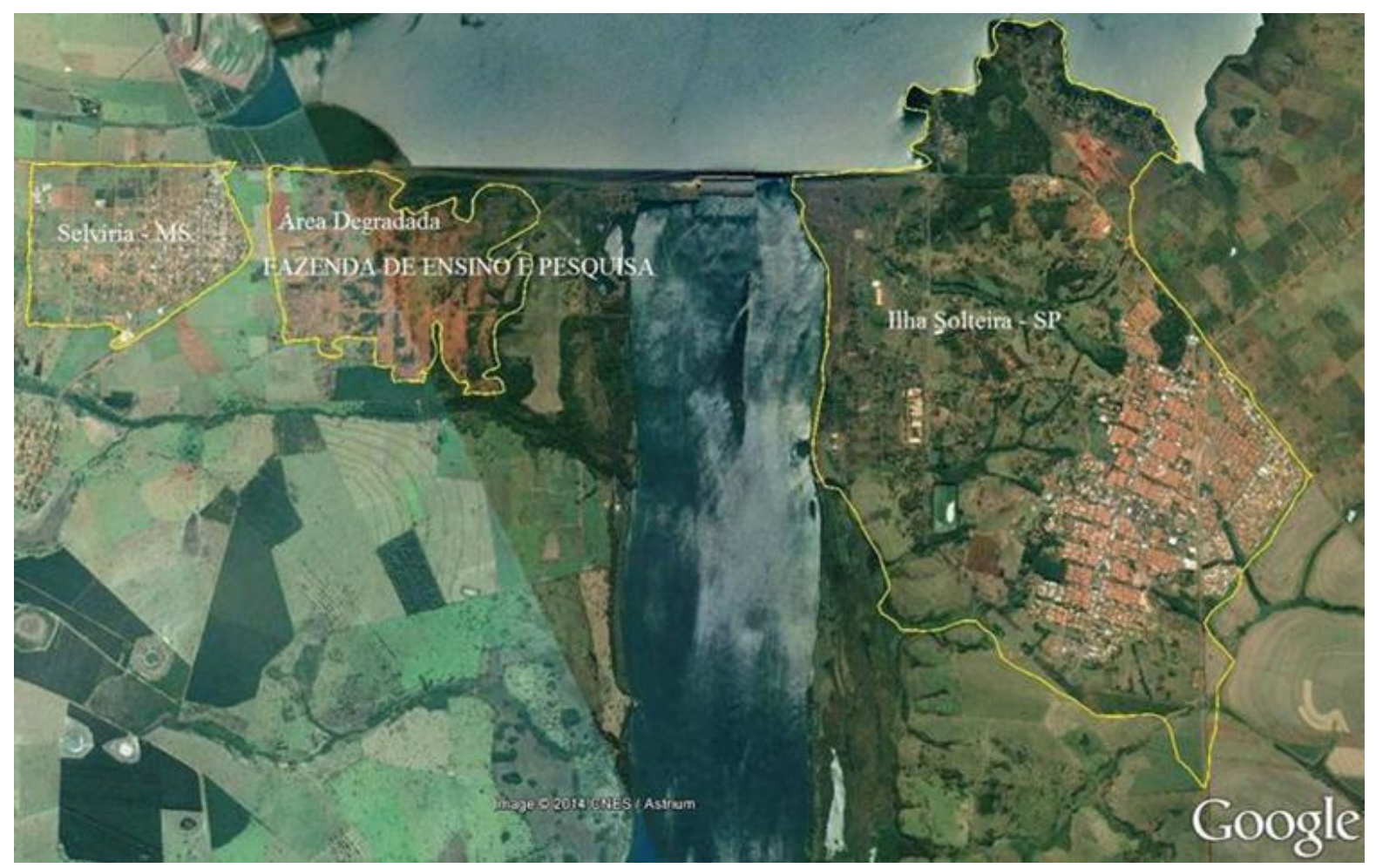

Figura 1. Imagem de satélite indicando a área experimental. Fonte: Google Earth (2014). 


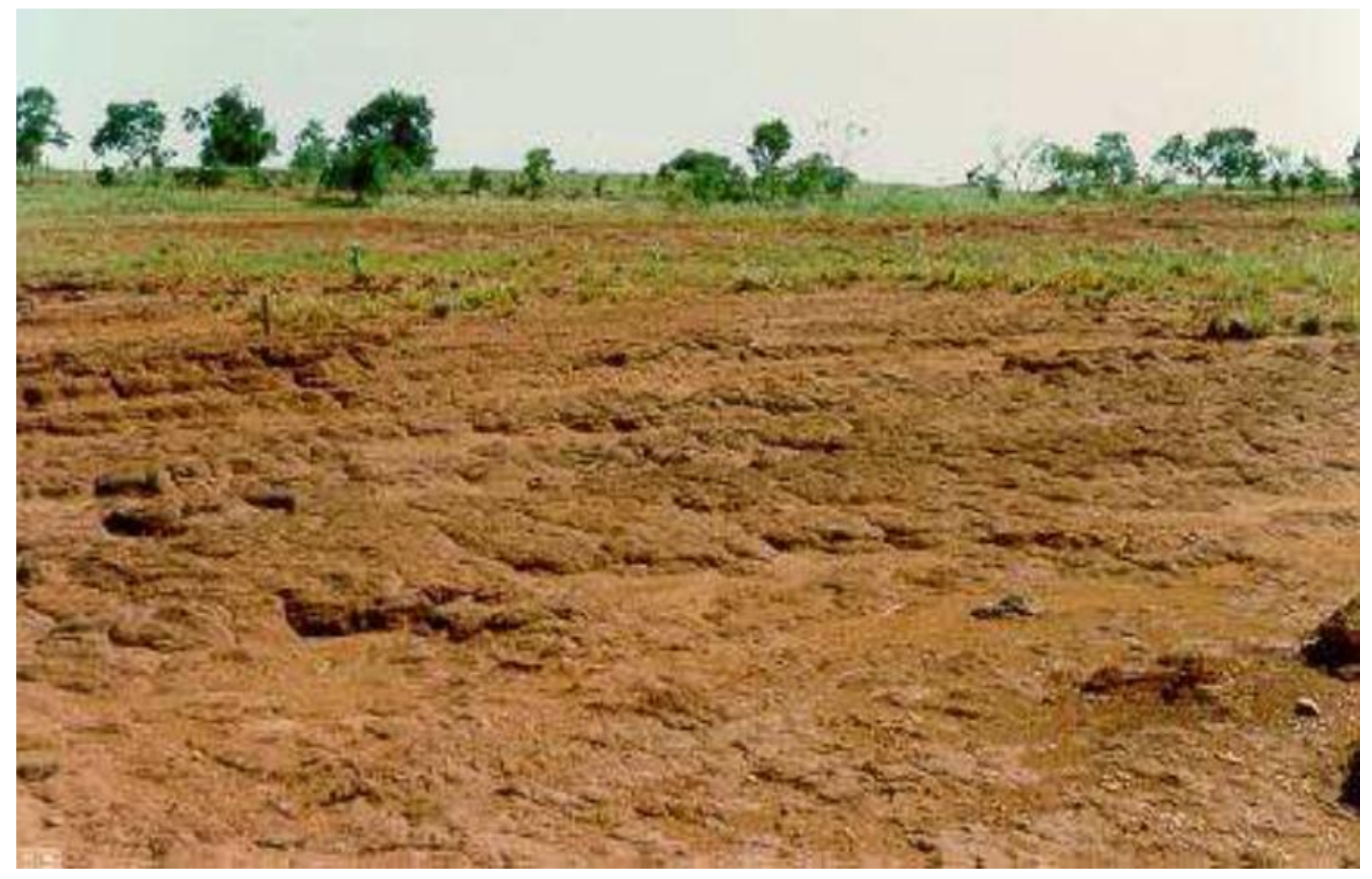

Figura 2. Subsolo exposto compactado (testemunha) e baixa presença de vegetação espontânea. Selvíria, MS. Fonte: Alves e Souza (2008).

Foi realizado levantamento florístico da área experimental e mensurados em todas as plantas existentes, o diâmetro à altura do solo (DAS) e a altura das plantas. As plantas novas foram identificadas e incluídas na planilha existente de trabalhos anteriores. O diâmetro das plantas foi mensurado com a utilização de um paquímetro a $0,10 \mathrm{~m}$ acima do nível do solo, e a altura das plantas foi obtida por meio do uso de um aparelho hipsômetro, tomando como base a gema apical das plantas. As mensurações de altura e diâmetro foram realizadas em outubro de 2011 e abril de 2012. Foi realizada a determinação da taxa de crescimento anual das plantas da área experimental, utilizando a seguinte fórmula:

$$
\text { Taxa de crecimento }=\frac{\text { valor da última avaliação }- \text { valor da } 1^{a} \text { avaliação }}{n^{o} \text { de dias entre a } 1^{a} \text { e a ultima avaliação }} \times 365
$$

Sendo que os números de dias entre a primeira e a última avaliação foram: outubro/2007 a outubro/2011 = 1459 dias acumulados. outubro/2007 a abril/2012 = 1640 dias acumulados.

Para a quantificação da produtividade de massa seca da $U$. decumbens, foram coletadas as plantas contidas em $1,00 \mathrm{~m}^{2}$, em três pontos de cada parcela. A massa de matéria seca foi avaliada por pesagem, após ser submetida à secagem em estufa com temperatura de 
60 a $70^{\circ} \mathrm{C}$ até atingir massa constante. A quantificação da massa foi realizada em dezembro de 2011 e março de 2012.

Os dados de produtividade de massa seca da $U$. decumbens foram analisados efetuando-se a análise de variância e teste de Tukey para as comparações das médias no nível de $5 \%$ de probabilidade. Foi utilizado o programa computacional SISVAR (FERREIRA, 2011) para a realização da análise estatística dos dados da forrageira. Os dados de taxa de crescimento das espécies não foram analisados estatisticamente porque as mesmas surgiram espontaneamente na área e, a sua maior ocorrência na mesma provavelmente, está associada com a direção do vento dominante e à proximidade com a planta-matriz.

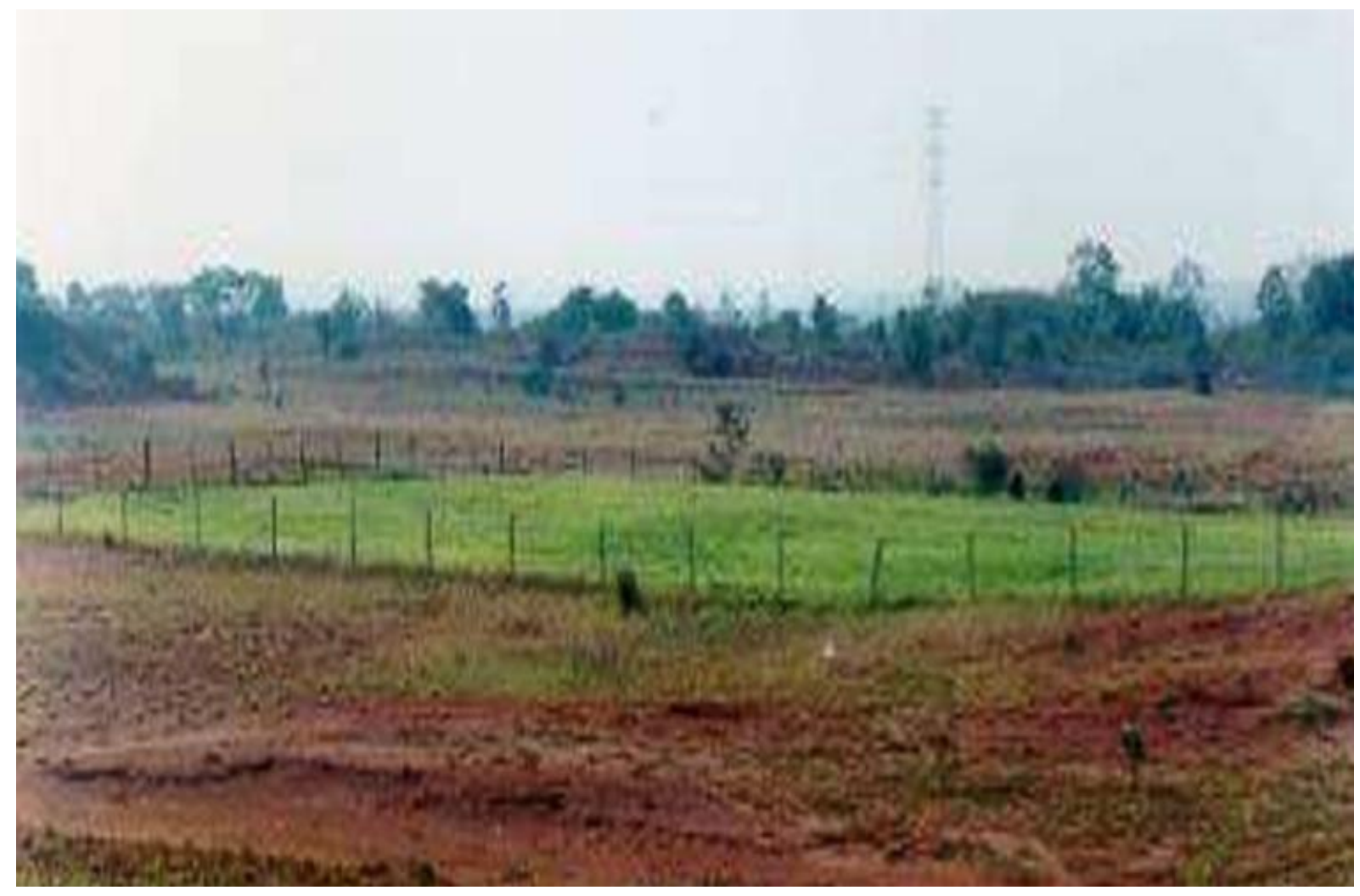

Figura 3. Vista geral da área experimental em 2001. Selvíria, MS. Fonte: Alves e Souza (2008).

\section{RESULTADOS E DISCUSSÃO}

Ao longo dos anos realizaram-se levantamentos florísticos (desde o ano de início do aparecimento da vegetação nativa (2007) até o ano de 2012) (Tabela 1), para verificar quais espécies estão surgindo e se desenvolvendo na área.

Em outubro de 2007 verificou-se a presença de 88 plantas de 3 espécies: Machaerium acutifolium Vogel (Jacarandá-do-campo), Solanum lycocarpum StHil (Lobeira) e Lippia lupulina Cham (Roseira-do-campo), dentre essas, 85 eram M. acutifolium. Em 2008 (Figura 4) as plantas da espécie $S$. lycocarpum não estavam mais presentes na área, enquanto que $M$. acutifolium haviam mais três plantas, e houve o surgimento de uma planta da espécie Curatella americana L (Lixeira), da família Dilleniaceae. Das três espécies que se regeneraram naturalmente na área de estudo, ao menos uma pertence à família Fabaceae $(M$. acutifolium). As Fabáceas são consideradas essenciais para o sucesso de recuperação de uma 
área degradada, pela sua rusticidade e alta capacidade de adicionar matéria orgânica ao solo (BONINI; ALVES, 2011).

No ano de 2009 havia 88 plantas na área, sendo que 86 eram M. acutifolium. Em 2010 foram identificadas 94 plantas, onde 91 eram M. acutifolium; e em 2011 existiam 102 plantas, das quais duas não eram M. acutifolium.

$\mathrm{Na}$ avaliação de 2012, observa-se que o número de plantas na área cresceu muito, constatando-se um total de 140 plantas, sendo que a maioria ainda continuou sendo da espécie M. acutifolium (131 indivíduos).

Depois de cerca de 5 anos, foi possível observar o surgimento de novas espécies antes inexistentes na área como Jacarandá-Caroba (Machaerium acutifolium), Tamanqueiro-docerrado (Aegiphila lhotzkyana) e o Murici (Byrsonima sp.).

Esse surgimento possivelmente se deu porque houve a dispersão das sementes dessas espécies, fazendo com que elas chegassem ao local do experimento. Também é importante levar em conta a rusticidade dessas espécies, principalmente do que já está presente em áreas degradadas circunvizinhas ao experimento e se desenvolvem muito bem nessas condições.

Algumas pesquisas já demonstraram que os processos de regeneração natural do Cerrado, em áreas degradadas, são relativamente mais bem sucedidos do que em regiões florestais (DURIGAN et al., 2011). Por meio desses processos naturais, o Cerrado leva aproximadamente 30 anos para atingir a biomassa anterior ao desmatamento (DURIGAN, 2005) dependendo é claro do grau de intensidade de degradação que a área sofreu.

A situação atual da área em recuperação, que está com uma densidade de 500 indivíduos $\mathrm{ha}^{-1}\left(\left(10.000 \mathrm{~m}^{2} \mathrm{X} 140\right.\right.$ plantas $\left.) / 2800 \mathrm{~m}^{2}\right)$ pode ser considerada promissora, pois Duriganet al. (2011) retratam que em área de Cerrado em regeneração natural, a densidade pode ser considerada suficiente quando for de pelo menos 500 plantas lenhosas ha ${ }^{-1}$. Porém quanto à diversidade que o autor cita ser suficiente, que deve ser de no mínimo 30 espécies, essa área ainda não alcançou essa diversidade, pois está com apenas 7 espécies diferentes, mas está a caminho de alcançar pois a cada ano surgem novas espécies.

Também se deve observar que o surgimento de novas espécies foi possível devido à condição físico-química do solo em recuperação. Pode-se observar a evolução positiva desses atributos em trabalhos anteriores realizados nesta mesma área por Alves e Souza (2008), que notaram um incremento no teor de magnésio, principalmente na camada superficial, e esse comportamento ocorreu devido a prática de adubação verde que promove a recuperação da fertilidade do solo, proporcionando aumento de matéria orgânica, da capacidade de troca catiônica e da disponibilidade de macro e micronutrientes.

Bonini e Alves (2012) também trabalhando em mesma área, relatam que os atributos físicos do solo (macroporosidade do solo, densidade do solo, resistência do solo à penetração, estabilidade de agregados em água e a infiltração de água no solo) estão sendo recuperados ao longo do tempo, e que os tratamentos de recuperação do solo foram eficientes ao longo do processo de recuperação e estão atingindo até a camada de 0,20 m do solo. Assim é possível notar que o desenvolvimento das espécies florestais presentes na área, e o sucesso da regeneração natural no local é consequência destes vários fatores e intervenções, todos integrados.

Com relação à dispersão de indivíduos na área, a dispersão se deu, provavelmente por ação de animais e do vento dominante que carreou sementes para dentro da área, devido à provável matriz da espécie Jacarandá-do-campo (Machaerium acutifolium Vogel) estar localizada bem no entorno da área experimental e na direção oposta à direção do vento dominante, assim essa foi à espécie que mais perpetuou na área. Foi observado também que existe no entorno da área experimental plantas de Lixeira (Curatella americana), Lobeira 
(Solanum lycocarpum), Murici (Byrsonima sp.), Jacarandá-caroba (Jacaranda caroba Vell) e Roseira-do-campo (Lippia lupulina Cham.),que provavelmente podem ser as matrizes desses regenerantes que surgiram dentro da área experimental.

Tabela 1. Levantamento florístico das espécies arbóreas presentes na área. Selvíria, MS.

\begin{tabular}{lcccccc}
\hline Espécies & 2007 & 2008 & 2009 & 2010 & 2011 & 2012 \\
\hline Jacarandá-do-campo (Machaerium & 85 & 88 & 86 & 91 & 100 & 131 \\
acutifolium Vogel) & 0 & 0 & 0 & 0 & 0 & 1 \\
Jacarandá-caroba (Jacaranda caroba Vell) & 0 & 1 & 1 & 2 & 1 & 2 \\
Lixeira (Curatella americanaL) & 2 & 0 & 0 & 0 & 0 & 3 \\
Lobeira (Solanum lycocarpum StHil) & 0 & 0 & 0 & 0 & 0 & 1 \\
Murici (Byrsonima sp.) & 1 & 1 & 1 & 1 & 1 & 1 \\
Roseira-do-campo (Lippia lupulina Cham.) & 0 & 0 & 0 & 0 & 0 & 1 \\
Tamanqueiro-do-cerrado (Aegiphila lhotzkyana) & 88 & 90 & 88 & 94 & 102 & 140 \\
\hline Total & & & & & & \\
\hline
\end{tabular}

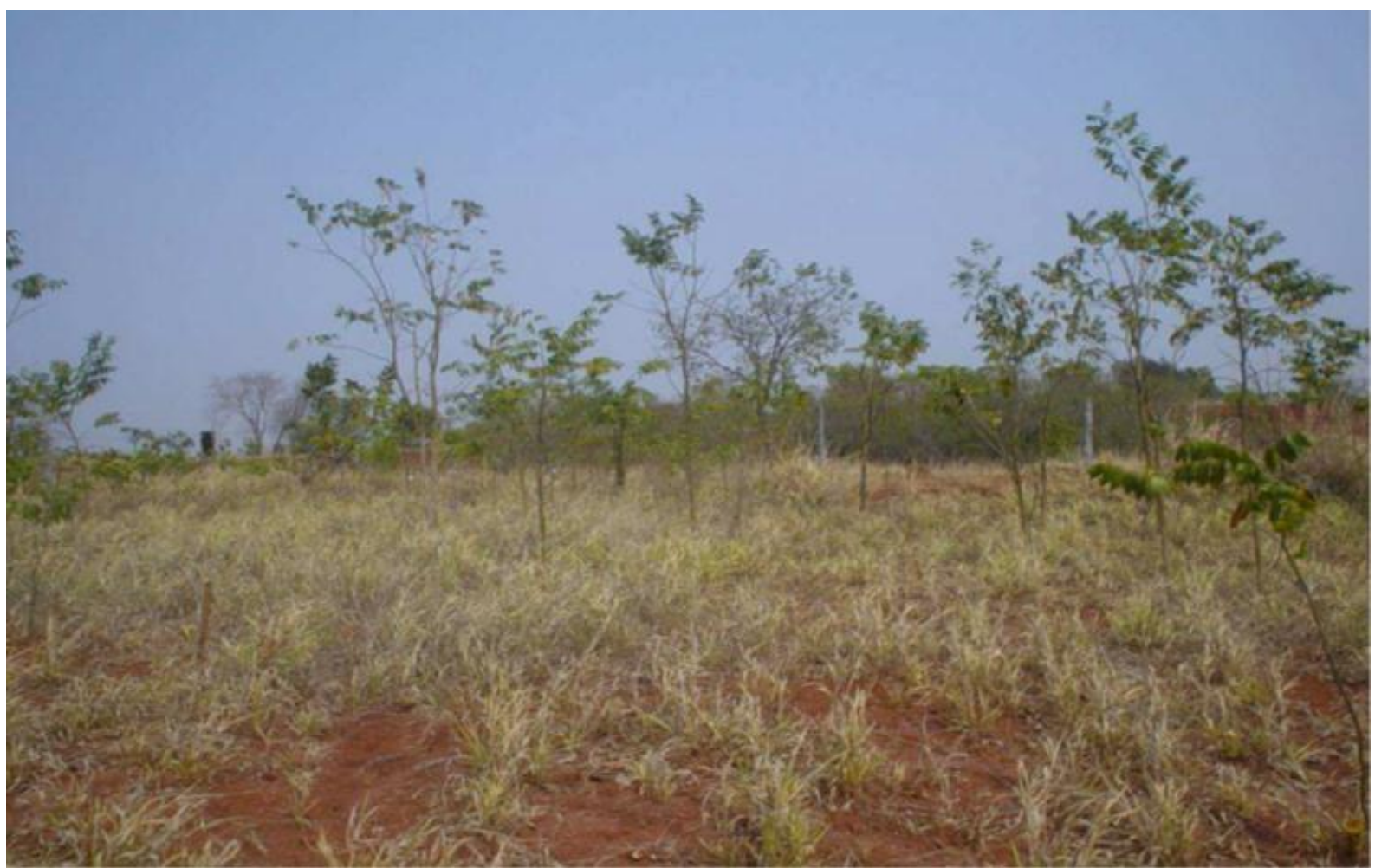

Figura 4. Vista geral da área experimental em 2008. Selvíria, MS. Fonte: Bonini e Alves (2011). 


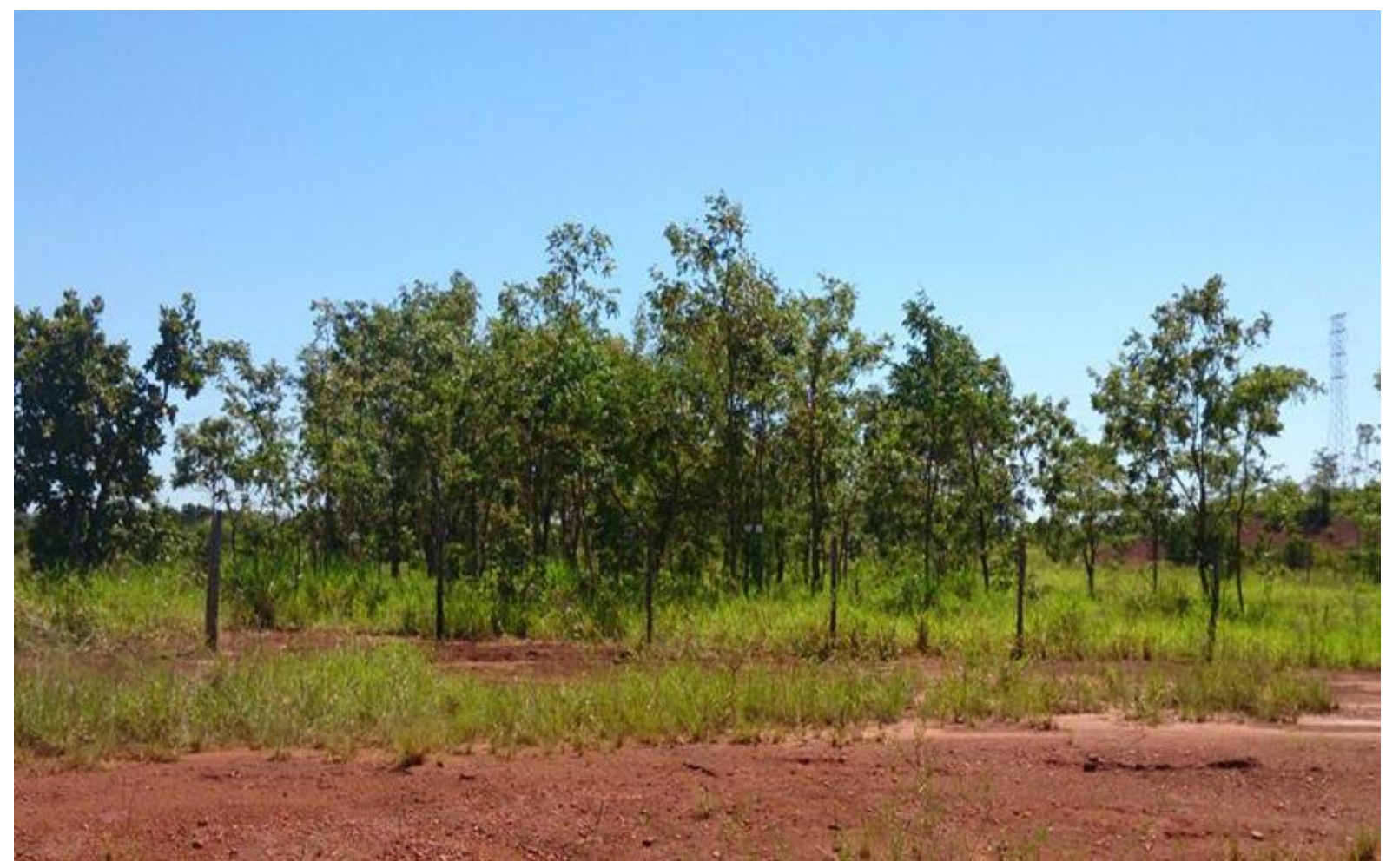

Figura 5. Vista geral da área experimental. Selvíria, MS, 2013. Fonte: Dados do próprio autor.

Analisando, de forma comparativa numericamente, a taxa de desenvolvimento no período de outubro/2007 até outubro/2011 e abril/2012 de Machaerium acutifolium Vogel (Jacarandá-do-campo), que é a espécie presente em maior número na área, nota-se que no tratamento MP/U em outubro/2011, obteve a maior taxa de crescimento (altura e diâmetro), e em abril/2012, esta cresceu mais no tratamento C+Ge+MP/U (Tabela 2).

Tabela 2. Taxa de crescimento de plantas da espécie Machaerium acutifolium Vogel (Jacarandá-do-campo),de outubro/2007 a outubro/2011 e abril/2012. Selvíria, MS.

\begin{tabular}{ccccc}
\hline \multirow{2}{*}{ Tratamento } & \multicolumn{2}{c}{ TC $^{*}$ out/2011 } & \multicolumn{2}{c}{ TC $^{*}$ - abr/2012 } \\
\cline { 2 - 5 } & Altura & Diâmetro & Altura & Diâmetro \\
\hline SM/U & 0,48 & 1,23 & 0,40 & 0,72 \\
MP/U & 0,75 & 1,77 & 0,14 & 0,26 \\
G/FP/U & 0,56 & 1,10 & 0,26 & 0,53 \\
$\mathrm{C}+\mathrm{MP} / \mathrm{U}$ & 0,65 & 1,18 & 0,29 & 0,66 \\
$\mathrm{C}+\mathrm{G} / \mathrm{FP} / \mathrm{U}$ & 0,53 & 1,00 & 0,26 & 0,51 \\
$\mathrm{C}+\mathrm{Ge}+\mathrm{MP} / \mathrm{U}$ & 0,34 & 0,54 & 0,50 & 0,74 \\
$\mathrm{C}+\mathrm{Ge}+\mathrm{G} / \mathrm{FP} / \mathrm{U}$ & 0,51 & 0,58 & 0,13 & 0,17 \\
\hline
\end{tabular}

TC* - Taxa de Crescimento. Sendo número de dias entre a primeira e a última avaliação: - (outubro/2007 a outubro/2011 = 1459 dias acumulados); e- (outubro/2007 a abril/2012 = 1640 dias acumulados). SM/U = Solo mobilizado até 1999, após implantada Urochloa; MP/U = Mucuna-preta até 1999 após substituída por Urochloa; G/FP/U = Guandu até 1994, após substituído por Feijão-de-porco e a partir de 1999 substituído por Urochloa; C+MP/U = Calcário+Mucuna-preta até 1999, após substituída por Urochloa; C+G/FP/U = Calcário+Guandu até 1994, após substituído por Feijão-de-porco e a partir de 1999 substituído por Urochloa; $\mathrm{C}+\mathrm{Ge}+\mathrm{MP} / \mathrm{U}=\mathrm{Calcário+Gesso+Mucuna-preta} \mathrm{até} 1999$ após substituída por Urochloa; C+Ge+G/FP/U = Calcário+Gesso Guandu, até 1994, após substituído por Feijão-de-porco e a partir de 1999 substituído por Urochloa.

Em todos os tratamentos de recuperação do solo houve acréscimo na altura e no diâmetro a $10 \mathrm{~cm}$ do solo, entretanto houve também um aumento significativo no número de 
indivíduos (plantas) provocando assim uma queda nas médias das alturas e diâmetros das plantas (Tabela 3 e 4).

Avaliações realizadas por Ferreira et al. (2007) acompanhando o desenvolvimento de espécies arbóreas em área degradada pela construção de uma Usina Hidrelétrica, relataram que as plantas da família Fabaceae apresentaram maiores alturas e maiores diâmetros médios de caule. Assim indivíduos dessa família de plantas são essenciais para acelerar o processo de recuperação de solos degradados, devido ao seu rápido crescimento vegetativo e seu sistema radicular pivotante, que promove o rompimento de camadas compactadas do perfil.

Tabela 3. Altura e diâmetro a $0,10 \mathrm{~m}$ do solo (DAS) de plantas da espécie Machaerium acutifolium Vogel (Jacarandá-do-campo) de outubro/2011. Selvíria, MS.

\begin{tabular}{ccc}
\hline Tratamento & Altura da planta $(\mathrm{m})$ & Diâmetro do caule $(\mathrm{cm})$ \\
\hline $\mathrm{SM} / \mathrm{U}$ & 3,98 & 7,88 \\
MP/U & 5,29 & 10,54 \\
$\mathrm{G} / \mathrm{FP} / \mathrm{U}$ & 4,96 & 8,24 \\
$\mathrm{C}+\mathrm{MP} / \mathrm{U}$ & 4,77 & 7,91 \\
$\mathrm{C}+\mathrm{G} / \mathrm{FP} / \mathrm{U}$ & 4,03 & 7,13 \\
$\mathrm{C}+\mathrm{Ge}+\mathrm{MP} / \mathrm{U}$ & 3,74 & 5,81 \\
$\mathrm{C}+\mathrm{Ge}+\mathrm{G} / \mathrm{FP} / \mathrm{U}$ & 4,63 & 6,38 \\
\hline
\end{tabular}

SM/U = Solo mobilizado até 1999, após implantada Urochloa; MP/U = Mucuna-preta até 1999 após substituída por Urochloa; G/FP/U = Guandu até 1994, após substituído por Feijão-de-porco e a partir de 1999 substituído por Urochloa; C+MP/U = Calcário+Mucuna-preta até 1999, após substituída por Urochloa $;$ C+G/FP/U = Calcário+Guandu até 1994, após substituído por Feijão-de-porco e a partir de 1999 substituído por Urochloa; C+Ge+MP/U= Calcário+Gesso+Mucuna-preta até 1999 após substituída por Urochloa; C+Ge+G/FP/U= Calcário+Gesso Guandu, até 1994, após substituído por Feijão-deporco e a partir de 1999 substituído por Urochloa.

Tabela 4. Altura e diâmetro a $0,10 \mathrm{~m}$ do solo (DAS) de plantas da espécie Machaerium acutifolium Vogel (Jacarandá-do-campo) de abril/2012. Selvíria, MS.

\begin{tabular}{ccc}
\hline Tratamento & Altura da planta $(\mathrm{m})$ & Diâmetro do caule $(\mathrm{cm})$ \\
\hline $\mathrm{SM} / \mathrm{U}$ & 4,32 & 6,20 \\
$\mathrm{MP} / \mathrm{U}$ & 2,93 & 4,67 \\
$\mathrm{G} / \mathrm{FP} / \mathrm{U}$ & 3,88 & 6,21 \\
$\mathrm{C}+\mathrm{MP} / \mathrm{U}$ & 3,46 & 6,15 \\
$\mathrm{C}+\mathrm{G} / \mathrm{FP} / \mathrm{U}$ & 3,08 & 5,09 \\
$\mathrm{C}+\mathrm{Ge}+\mathrm{MP} / \mathrm{U}$ & 4,23 & 6,90 \\
$\mathrm{C}+\mathrm{Ge}+\mathrm{G} / \mathrm{FP} / \mathrm{U}$ & 3,15 & 4,87 \\
\hline
\end{tabular}

SM/U = Solo mobilizado até 1999, após implantada Urochloa; MP/U = Mucuna-preta até 1999 após substituída por Urochloa; G/FP/U = Guandu até 1994, após substituído por Feijão-de-porco e a partir de 1999 substituído por Urochloa; C+MP/U = Calcário+Mucuna-preta até 1999, após substituída por Urochloa; C+G/FP/U = Calcário+Guandu até 1994, após substituído por Feijão-de-porco e a partir de 1999 substituído por Urochloa; C+Ge+MP/U= Calcário+Gesso+Mucuna-preta até 1999 após substituída por Urochloa; C+Ge+G/FP/U= Calcário+Gesso Guandu, até 1994, após substituído por Feijão-deporco e a partir de 1999 substituído por Urochloa.

As plantas encontradas podem ter chegado à área experimental por meio da dispersão das sementes da planta adulta, trazidas pelo vento. Isso evidencia a importância da dispersão nos processos de regeneração de uma área degradada. Portanto, pode-se dizer que para a espécie Machaerium acutifolium Vogel, a variável número de plantas foi influenciada pela proximidade da planta-matriz em relação às parcelas experimentais. Uma vez que, o maior número de plantas desta espécie foi encontrado nas parcelas mais próximas da planta adulta. 
Bonini e Alves (2011), trabalhando nesta mesma área obtiveram maiores produções para o tratamento $\mathrm{C}+\mathrm{MP} / \mathrm{U}$, tratamento que ficou em segundo lugar na produção de matéria seca de $U$. decumbens neste trabalho. A produtividade de massa seca de $U$. decumbens mostra que este solo está sendo recuperado com produtividades semelhantes às encontradas por Bonini e Alves (2012) nesta mesma área de solo degradado.

É de suma importância a utilização da $U$. decumbens no processo de recuperação de áreas degradadas, pois ela pode proteger o solo do impacto das chuvas, fornece matéria orgânica que favorece a formação de agregados, facilitando a penetração das raízes e a vida microbiana (KITAMURA et al., 2008).

Em relação à produtividade de massa seca da $U$. decumbens (Tabela 5), analisando o teste $\mathrm{F}$ para tratamento houve significância a $5 \%$ de probabilidade, já para épocas de avaliação e interação tratamento $x$ época, não houve significância. Comparando-se os tratamentos de recuperação, o tratamento $\mathrm{C}+\mathrm{G} / \mathrm{FP} / \mathrm{U}$ e o $\mathrm{SM} / \mathrm{U}$ obtiveram respectivamente maior e menor produção de massa seca da $U$. decumbens. Dos tratamentos com guandu o tratamento com calcário resultou em maior produtividade, e dos tratamentos com mucuna as combinações resultaram em maiores produtividades, sendo o tratamento com menor produtividade aquele onde foi utilizado apenas mucuna, sem nenhum outro adubo-verde ou corretivo associado. Percebe-se que as diferentes épocas de corte não estão influenciando na produtividade da forrageira, somente os adubos verdes estão tendo essa função.

Tabela 5. Valores de F, DMS - 5\%, CV (\%) e valores médios de massa seca da Urochloa decumbens $\left(\mathrm{kg} \mathrm{ha}^{-1}\right)$ nos tratamentos estudados e épocas de avaliação. Selvíria, MS.

\begin{tabular}{|c|c|}
\hline Causas de variação & Valor de F \\
\hline Tratamento & $2,099^{*}$ \\
\hline Época & $1,057^{\mathrm{ns}}$ \\
\hline Tratamento $x$ Época & $0,660^{\mathrm{ns}}$ \\
\hline CV $-\%-$ & 19,010 \\
\hline Tratamentos & Produtividade de massa seca \\
\hline $\mathrm{SM} / \mathrm{U}$ & $2085 B$ \\
\hline $\mathrm{MP} / \mathrm{U}$ & $2461 \mathrm{AB}$ \\
\hline $\mathrm{G} / \mathrm{FP} / \mathrm{U}$ & $2597 \mathrm{AB}$ \\
\hline $\mathrm{C}+\mathrm{MP} / \mathrm{U}$ & $2708 \mathrm{AB}$ \\
\hline $\mathrm{C}+\mathrm{G} / \mathrm{FP} / \mathrm{U}$ & $3111 \mathrm{~A}$ \\
\hline $\mathrm{C}+\mathrm{Ge}+\mathrm{MP} / \mathrm{U}$ & $2557 \mathrm{AB}$ \\
\hline $\mathrm{C}+\mathrm{Ge}+\mathrm{G} / \mathrm{FP} / \mathrm{U}$ & $2636 \mathrm{AB}$ \\
\hline DMS-5\% & 927,531 \\
\hline Época & Produtividade de massa seca \\
\hline Dezembro/2011 & $2676 \mathrm{~A}$ \\
\hline Março/2012 & $2512 \mathrm{~A}$ \\
\hline DMS $-5 \%$ & 322,670 \\
\hline \multicolumn{2}{|c|}{$\begin{array}{l}\text { Médias seguidas de letras iguais na coluna não diferem entre si pelo teste de Tukey a } 5 \% \text { de probabilidade. } \mathrm{SM} / \mathrm{U}=\mathrm{Solo} \\
\text { mobilizado até } 1999 \text {, após implantada Urochloa; } \mathrm{MP} / \mathrm{U}=\text { Mucuna-preta até } 1999 \text { após substituída por Urochloa; G/FP/U = } \\
\text { Guandu até 1994, após substituído por Feijão-de-porco e a partir de } 1999 \text { substituído por Urochloa; C+MP/U = } \\
\text { Calcário+Mucuna-preta até 1999, após substituída por Urochloa; } \mathrm{C}+\mathrm{G} / \mathrm{FP} / \mathrm{U}=\mathrm{Calcário+Guandu} \text { até } 1994 \text {, após substituído } \\
\text { por Feijão-de-porco e a partir de } 1999 \text { substituído por Urochloa; } \mathrm{C}+\mathrm{Ge}+\mathrm{MP} / \mathrm{U}=\text { Calcário+Gesso+Mucuna-preta até } 1999 \\
\text { após substituída por Urochloa; } \mathrm{C}+\mathrm{Ge}+\mathrm{G} / \mathrm{FP} / \mathrm{U}=\text { Calcário+Gesso Guandu, até } 1994 \text {, após substituído por Feijão-de-porco e a } \\
\text { partir de } 1999 \text { substituído por Urochloa. }\end{array}$} \\
\hline
\end{tabular}


É possível observar também que esta espécie não é competitiva, já que foram encontradas outras plantas aos arredores da planta matriz, podendo afirmar que a mesma oferece condições para o desenvolvimento de outras espécies. Não foi encontrada nenhuma planta da mesma espécie (M. acutifolium) próximo da planta matriz, evidenciando que a área experimental (ambiente em recuperação), criou condições benéficas para o estabelecimento da espécie $M$. acutifolium, uma vez que a área de estudo estava em processo de recuperação há 19 anos, apresentando melhores condições em relação às condições encontradas fora do experimento.

As gramíneas quase sempre estão inclusas no processo de recuperação de solos degradados, pois são capazes de acrescentar grande parte de matéria orgânica ao solo, desenvolvem-se rapidamente e possuem um sistema radicular fasciculado com grande volume de raízes que se renova constantemente.

\section{CONCLUSÕES}

Os tratamentos de recuperação do solo estão sendo promissores e a ocorrência de espécies arbóreas de Cerrado e os seus desenvolvimentos têm sido bons indicadores de recuperação do mesmo.

Das sete espécies de plantas que se regeneraram naturalmente dentro da área experimental, a espécie que mais se adaptou foi o Jacarandá-do-campo (Machaerium acutifolium Vogel).

Os tratamentos para recuperação do solo estão agindo de forma semelhante na produtividade da forrageira Urochloa decumbens. O tratamento feijão-de-porco após o guandú, com aplicação de calcário no solo, foi mais eficiente quando comparado ao tratamento Solo mobilizado com vegetação espontânea.

\section{AGRADECIMENTOS}

Agradecimentos à FAPESP pelo apoio financeiro concedido.

\section{REFERÊNCIAS BIBLIOGRÁFICAS}

ALVES, M. C.; SOUZA, Z. M. Recuperação de área degradada por construção de hidroelétrica com adubação verde e corretivo. Revista Brasileira de Ciência do Solo, Viçosa-MG, v. 32, n. 6, p. 2505-2516, 2008. Disponível em: $<$ http://www.sidalc.net/cgibin/wxis.exe/?IsisScript=SCBR.xis\&method=post\&formato=2 \&cantidad=1\&expresion=mfn=019608> . Acesso em: 11 jan. 2014.

ANAND, M.; DESROCHERS, R. E. Quantification of restoration success using complex systems concepts and models. Conservation Biology, Hoboken, USA, v. 12, n. 1, p. 117-123, 2004.

Disponívelem:<http://www.scielo.br/scielo.php?script=sci_nlinks\&ref=064\&pid=S01006762 207001502\&lng=pt $>$. Acesso em: 20 fev. 2014.

ARGENTON, J.; ALBUQUERQUE, J. A.; BAYER, C.; WILDNER, L. P. Comportamento de atributos relacionados com a forma da estrutura de Latossolo vermelho sob sistemas de preparo e plantas de cobertura. Revista Brasileira de Ciência do Solo, Viçosa-MG, v. 29, n. 3, p. 425-435, 2005. Disponível em: <http://www.scielo.br/pdf/rbcs/v29n3/25743.pdf>. Acesso em: 20 abr. 2014. 
BONINI, C. S. B.; ALVES, M. C. Recuperação das propriedades físicas do solo por meio de adubos verdes, calagem, gesso, pastagem e espécies de ocorrência espontânea. Revista Brasileira de Ciência do Solo, Viçosa-MG, v. 35, n. 4, p.429-437, 2011.

BONINI, C. S. B.; ALVES, M. C. Qualidade física de um Latossolo Vermelho em recuperação há dezessete anos. Revista Brasileira de Engenharia Agrícola e Ambiental, Campina Grande - PB, v. 16, n. 4, p. 329-336, 2012. Disponível em: <http://www.scielo.br/scielo.php?pid=S1415-43662012000400001\&script=sci_arttext $>$.

Acesso em: 02 mar. 2014.

CORRÊA, R. S.; LEITE, L. L.; BASTOS, E. K. Dinâmica da degradação e da regeneração. In: CORRÊA, R. S.; MELO FILHO, B. (Orgs.). Ecologia e recuperação de áreas degradadas no cerrado. Brasília-DF: Paralelo 15, 1998. p. 49-63.

DEMATTÊ, J. L. I. Levantamento detalhado dos solos do Campus Experimental de Ilha Solteira (SP). Piracicaba-SP, 1980. 131p. (Mimeografado)

DURIGAN, G. Restauração da cobertura vegetal em região de domínio do cerrado. In: GALVÃO, A. P. M.; PORFÍRIO, S. V. (Org.). Restauração florestal: fundamentos e estudos de caso. 1. ed. Colombo-PR: Embrapa Florestas, 2005. p.103-118.

DURIGAN, G.; MELO, A. C. G.; MAX, J. C. M.;VILAS BOAS, O.; CONTIERI, W. A.; RAMOS, V. S. Manual para recuperação da vegetação de cerrado. 3.ed. São Paulo-SP: SMA, 2011. $19 \quad 19$ p. 19 Disponível <http://www.sigam.ambiente.sp.gov.br/sigam2/Repositorio/222/Documentos/Manual_recuper acao_cerrado.pdf $>$. Acesso em: 30 mar. 2014.

FERREIRA, W. C.; BOTELHO, S. A.; DAVIDE, A. C.; FARIA J. M. R. Avaliação do crescimento do estrato arbóreo de área degradada revegetada à margem do Rio Grande, na Usina hidrelétrica de Camargos, MG. Revista Árvore, Viçosa-MG, v. 31, n.1, p. 177 185.2007 .

FERREIRA, D. F. Sisvar: a computer statistical analysis system. Ciência e Agrotecnologia, Lavras-MG, v. 35, n. 6, p. 1039-1042, 2011.

GOOGLE EARTH. Guia do usuário. Disponível em: <http://earth.google.com/intl/ptBR/userguide/v4/ug_toc.html>. Acesso em: 21 abr. 2014.

KITAMURA, A. E.; ALVES, M. C.; SUZUKI, L. G. A. S.; GONZALEZ, A. P. Recuperação de um solo degradado com aplicação de adubos verdes e lodo de esgoto. Revista Brasileira de Ciência do Solo, Viçosa-MG, v. 32, n. 1, p. 405-416, 2008.

MARTINS, C. R.; LEITE, L. L.; HARIDASAN, M. Capim - gordura (Melinis minutiflora P. Beauv.), uma gramínea exótica que compromete a recuperação de áreas degradadas em unidades de conservação. Revista Árvore, Viçosa-MG, v. 28, n. 5, p. 6-12, 2004. Disponível em: <http://www.scielo.br/scielo.php?pid=S0100-676224000500014\&script=sci_arttext >. Acesso em: 28 jan. 2014.

MELO, W.J.; MARQUES, M.O.; SANTIAGO, G.; CHELLI, R.A.; LEITE, S.A.S. Efeito de doses crescentes de lodo de esgoto sobre frações da matéria orgânica e CTC de um Latossolo cultivado com cana-de-açúcar. Revista Brasileira de Ciência do Solo, Viçosa-MG, v. 18, n. 1, p. 449-455, 2007.

PEREIRA, A. R. Como selecionar plantas para áreas degradadas e controle de erosão. 2 . ed. Belo Horizonte: Ed. FAPI, 2008. 239 p. Disponível em: $<$ http://deflor.com.br/downloads/LIVROSele\%C3\%A7\%C3\%A3o_de_esp\%C3\%A9cies_para _\%C3\%A1reas_degradadas.pdf>. Acesso em: 15 abr. 2014. 
RAMOS, L. A.; NOLLA, A.; KORNDÖRFER, G. H.; PEREIRA, H. S.; CAMARGO, M. S. Reatividade de corretivos da acidez e condicionadores de solo em colunas de lixiviação. Revista Brasileira de Ciência do Solo, v. 30, n. 5, p. 849-857, 2006. Disponível em: <http://www.scielo.br/pdf/rbcs/v30n5/11.pdf>. Acesso em: 15 mar. 2014.

SANTOS, H. G.; JACOMINE, P. K. T.; ANJOS, L. H. C.; OLIVEIRA, V. A.; LUMBRERAS, J. F.; COELHO, M. R.; ALMEIDA, J. A.; CUNHA, T. J. F.; OLIVEIRA, J. B. Sistema Brasileiro de Classificação de Solos. 3. ed. Brasília: EMBRAPA, 2013. 353p.

SILVA, L.C.R.; CORRÊA, R.S. Sobrevivência e crescimento de seis espécies arbóreas submetidas a quatro tratamentos em área minerada no cerrado. Revista Árvore, Viçosa-MG, v. 32, n. 4, p. 731-740, 2008. Disponível em: <file:///Sobrevivencia-e-Crescimento-de-SeisEspecies-Arboreas-Submetidas-a-Quatro-Tratamentos-em-Area-Minerada-no-Cerrado-.pdf $>$. Acesso em: 03 fev. 2014.

VALCARCEL, R.; SILVA, Z. S. A eficiência conservacionista de medidas de recuperação de áreas degradadas: proposta metodológica. Revista Floresta, Curitiba-PR, v. 27, n. 1/2, p. 101-114, 2000.

Disponível

em:

<http://www.ufrrj.br/institutos/if/lmbh/pdf/publica\%C3\%A7ao_revista/revista04.pdf>.

Acesso em: 10 fev. 2014.

VIEIRA, D. S.; BORGES, I. B.; LIMA, G. J. E. O. Diagnóstico de parâmetros de fertilidade dos solos da região sudeste. Revista Factu Ciência, Unaí-MG, v. 13, n. 7, p. 7-26, 2007. Disponível em: <http://www.factu.br/Arquivos/FactuCiencia/13.pdfp/27>. Acesso em: 03 mar. 2014. 